\title{
Part One: Introduction to the General Structures of Experience
}

\section{Chapter I: Perception}

The study of perception constitutes one of psychology's major preoccupations, and it is easy to see why: perception is indeed a primordial faculty that underpins our insertion in the world and all of our relations with other people. No attempt to understand any phenomenon of relations between humans and the world (and the film experience is precisely such a relation) can do without a general theory of perception. Whence the primary position reserved to the present chapter.

We will first see how the faculty of perception was conceived by the psychological tradition. More precisely, we will try to clarify the principles or, rather, the prejudices which have presided over the elaboration of certain classical theories.

This preamble will then help us to better recognize the phenomenological perspective, a perspective in which this study in its entirety is situated, and which, we suggest, will allow us to discover the true meaning of perception.

\section{The Point of View of Traditional Psychology}

Traditional thought unreservedly acknowledged the distinction between the world and the individual. It placed the individual between parentheses and bestowed it with the necessary functions for its integration into an environment. In this perspective, the world was always presented first, as an existing reality external to the individual, and whose truth the individual had to conquer.

As a victim of this prejudice, psychology posited the notion of sensation - an impression corresponding to a sensory excitation issued from a fragment of external reality - and made of perception a cognitive operation destined to procure for us, on the basis of a mosaic of sensations, the most adequate representation of this world in itself, present before anything else.

Perception, as Piéron's dictionary of psychology indicates, had become a "moment of sensory awareness of external objects and events which have given birth to sensations of varying number and complexity."

As for the perception of other people, traditional psychology was also incapable of conceiving it without the support of a cognitive operation. For this psychology, totally impregnated by the classical distinctions between 
mind and body, individual and world, the 'psychic fact' appeared as an internal reality accessible only to the subject who feels it, thanks to a process of introspection. Consequently, in order to apprehend this same 'psychic fact' in other people, we had to establish, by means of a totally intellectual operation, a relation between the 'psychic fact' and its external manifestations, manifestations which we have also experienced ourselves, and which constitute the only reality accessible to other people.

Finally, when this same psychology had to take stock of the communications existing between people, it had to have recourse to some motivation, function, or even instinct of sociability. The individual, conceived of as an individualized entity, an interiority closed in on itself, could not logically communicate with its kin without the intervention of these hypothetical internal forces. Thus, understanding other people involved intelligently reading the objective signs of their comportment, and communicating with them involved responding to a motivation strong enough to break the solitude of an otherwise quite self-sufficient being.

We can see that the conceptions that we have just briefly recalled are so many theoretical constructions built on what the phenomenologists have called the 'prejudice of the world.' There was still, at the origin of all reasoning, the individual and the objective world, the closed consciousness of the subject and the others. All the efforts of psychology consisted, then, of linking the terms thus defined, and explaining the de facto relations existing between individuals and the world, as well as among individuals themselves.

And yet, we should ask ourselves whether it was arbitrary to thus dissociate the terms. Was there not a way of relating to the world, and to other people, that was more fundamental than what traditional thought could define?

Is the human being, conceived of as an individualized entity, not a pure abstraction, an invention of the scientific attitude with no bearing on lived experience?

In the past, psychologists ignored these questions, but they have since been revealed to be of major interest in modern psychology, which has been considerably revitalized by the contributions of phenomenological reflection.

A quick analysis of the positions of phenomenology will enable us to understand the most important facets of perceptive phenomena.

\section{The Findings of Phenomenology}

Born in Germany with Edmund Husserl and disseminated in France by Jean-Paul Sartre and Maurice Merleau-Ponty, phenomenology is above all 
a method aimed at describing our immediate experience. Renouncing, at least provisionally, the theoretical explanations that reason or scientific intelligence have been able to construct, it represents a return to the lived experience of phenomena, an effort to recover a direct contact with the world such as it is, before any analysis that we can make of it, and any explanation that we can give of it.

As Merleau-Ponty has noted:

It is the attempt to provide a direct description of our experience such as it is, and without any consideration of its psychological genesis or of the causal explanations that the scientist, historian, or sociologist might offer of that experience... ${ }^{2}$

To return to the things themselves is to return to this world prior to knowledge, this world of which knowledge always speaks, and this world with regard to which every scientific determination is abstract, signitive and dependent, just like geography with regard to the landscape where we first learned what a forest, a meadow, or a river is. ${ }^{3}$

The lessons gained by the phenomenological method are so important that they have profoundly renewed our understanding of what it means to be human. Psychology and psychoanalysis, such as they are presently conceived by numerous practitioners (Angelo Hesnard, Jacques Lacan, etc.), have been considerably enriched by this new mode of thinking.

From the point of view that occupies us here, it is the contribution of the method concerning perception - perception in general and, more specifically, the perception of other people - that is of primary interest to us. In this regard, how does phenomenological reflection proceed when it comes to perception?

Rather than postulating, as premises for analysis, the individual and the world as separate entities, and trying to explain how one can represent the other to itself, we are concerned here, before anything else, with locating the experience of the perceiving subject in order to describe it and make it explicit.

In this perspective, the perception of the world is revealed as something totally different from the mental organization of a sum of sensations. The very notion of sensation seems unjustifiable in the face of experiential data.

Gestalt psychologists had already shown that what we perceive in a concrete and immediate manner is not the accumulation of sensations, but forms and structures of the whole, which are organized without the 
involvement of our intelligence. Let us quote, here, some particularly enlightening lines from Merleau-Ponty:

Broadly speaking, we should think of it [perception] not as a mosaic but as a system of configurations. Groups rather than juxtaposed elements are principal and primary in our perception. We group the stars into the same constellations as the ancients, yet it is a priori possible to draw the heavenly map many other ways. Given the series:

ab cd ef gh ij

we will always pair the dots according to the formula a-b, c-d, e-f, etc., although the grouping $\mathrm{b}-\mathrm{c}, \mathrm{d}-\mathrm{e}, \mathrm{f}-\mathrm{g}$, etc. is equally probable in principle. [...]

The same type of analysis can be applied to hearing: it will simply be a matter of temporal forms rather than spatial ones. A melody, for example, is a figure of sound and does not mingle with the background noises (such as the siren one hears in the distance during a concert) which may accompany it. The melody is not a sum of notes, since each note only counts by virtue of the function it serves in the whole, which is why the melody does not perceptibly change when transposed, that is, when all its notes are changed while their interrelationships and the structure of the whole remain the same. On the other hand, just one single change in these interrelationships will be enough to modify the entire make-up of the melody. Such a perception of the whole is more natural and more primary than the perception of isolated elements. [...]

Therefore analytical perception, through which we arrive at absolute value of the separate elements, is a belated and rare attitude - that of the scientist who observes or the philosopher who reflects. The perception of forms, understood very broadly as structure, grouping or configuration should be considered our spontaneous way of seeing. ${ }^{4}$

We can see, with the collapse of the notion of sensation, that there is also an abandonment of the idea of the intervention of the intelligence in the perceptive act. To perceive is not to think, reason, or judge. Far from being the sketch-outline of a knowledge that is elaborated on the basis of a sum of elementary data, perception attests, on the contrary, to a form of relating to the world that is more immediate and more primitive than 
that described by analytic thought, basing itself on supposedly objective elements.

As Merleau-Ponty, once more, writes:

I do not think the world in the act of perception: it organizes itself in front of me. When I perceive a cube, it is not because my reason sets the perspectival appearances straight and thinks the geometrical definition of a cube with respect to them. I do not even notice the distortions of perspective, much less correct them; I am at the cube itself in its manifestness through what I see. [...]

Perception is not a sort of beginning science, an elementary exercise of the intelligence; we must rediscover a commerce with the world and a presence to the world which is older than intelligence. ${ }^{5}$

At the end of the day, perceptive consciousness can no longer be conceived of as a closed entity that reasons in order to give itself a reality that is external to itself. When we return to first-person lived experience, perceptual consciousness first appeared as a relationship with the world, and the world perceived as that which is primordial in our existence, as a datum, given no thought, which is always 'already there,' and from which all knowledge is drawn. The primary element, however, is not the outside world, on the one hand, and the individual, on the other hand; it is perception itself as a primordial relationship with the world.

What we have just said about perception in general reveals itself to be just as correct when we look at the particular problem of the perception of other people.

Indeed, a return to lived experience evidently shows us that, no more than perception in general, the perception of other people is neither an operation nor a function of our intelligence, but an immediate datum. It is because the old psychology had conceived of the psychic fact as an internal reality only accessible by introspection that it had been obliged to carry out an intelligent reading of the external signs of the perception of other people, referring to a signified that is in itself inaccessible.

And yet, what does the introspection on these claimed internal psychic realities teach us, given that they are buried deep within the individual consciousness?

At the very most, there are some indications of a physiological nature, or certain qualitative nuances relating to a psychological state. We can say, for example, that emotion is an affective reaction of a certain intensity normally 
accompanied by vegetative manifestations. We could equally distinguish different types of emotion and nuance them by qualifying them according to their intensity or their quality. Thus, we speak of joy or sorrow, love or disgust, rage or fear (intense fear or quiet fear). But once we have said all this, we have still not understood the significance of emotion, for nothing, in these objective descriptions, gives us its meaning.

On the contrary, emotion becomes clearly intelligible when we envisage it as a form of behavior or comportment, a modification of our relations with other people. Rage, for example, as Jean-Paul Sartre has shown, is nothing but symbolic behavior destined to accomplish in the imaginary what we are incapable of accomplishing in reality. ${ }^{6}$

We can see that, to grasp the meaning of emotion, we must think of it as a form of comportment. In other words, we must think of it in the same manner as the emotion of another person whom we can observe. This signifies that the emotion is immediately perceptible in our bodily attitude, and thus that other people, and their comportment, are always clearly shown to us.

The psychic fact as a fundamental internal reality whose bodily manifestations would only be epiphenomena does not exist. Once again, consciousness is not an entity withdrawn from the world, one of whose possibilities would be to secrete psychic facts, which only have an external appearance through a collection of signs to be intelligently decoded. What is primordial is the beings who are in the world from the start, and who have this quality in common with each other, beings who are always placed on the same terrain of activities, and whose comportment is given with all their signification as figures detaching themselves from the background.

These considerations concerning the perception of other people are of fundamental importance for the comprehension of the problems posed by the relations between individuals and, on this basis, the problem of identification.

Indeed, if the perception of other people is an immediate given, if it has no need for any involvement of the faculties of knowledge to be realized, and if it is the primordial datum for a consciousness thrown into the world and no longer withdrawn from it, we can see that there is no longer any need for having recourse to a hypothetical function or motivation to explain the interactions between individuals. The link to other people no longer poses a problem because it now appears as a primary datum, as one of the dimensions of our existence. Once again, it is because it had conceived of man as a consciousness isolated from the world that the old psychology had been obliged to make the link with other people the result of an internal drive and thus make social relations a secondary formation. 
In reality, as Merleau-Ponty states, "our relation to the social, like our relation to the world, is deeper than every explicit perception and deeper than every judgment. [...] We return to the social world with which we are in contact through the simple fact of our existence, and that we inseparably bear along with us prior to every objectification."

Man is above all a social being, a node of relations, a being ineluctably linked with other people, and the nature of this link, in its original form, is what we call intersubjectivity.

Let us make some comments on this last notion.

The perception of other people, we said, is an immediate given. That is to say, in any encounter with another person, I directly grasp the signification of their behavior, not through a cognitive operation, but through an immediate apprehension of their comportment. I grasp their intentions and, in a way, they become my own. Correlatively, in this same encounter, I appear to the other person in the same way that they appear to me. The other person reads my behavior. My intentions become, in some way, lived by another consciousness and cease to belong only to me. This kind of conscious coexistence of several subjectivities is first sketched out in every encounter. This is what we call intersubjectivity, the primordial link by means of which I am to other people as they are to me.

Regarding the philosophical problem posed by the dialectic of "the Alter and the Ego," Hesnard wrote the following lines, which have much to teach us about the nature of intersubjectivity:

In order for the dialectic of the Ego and the Alter Ego to be possible, they both must be defined by their situation. Discovering not only my presence for-myself, I must also discover the possibility of an alien actor "through a kind of internal weakness that prevents me from being absolutely individual and exposes me to the gaze of others" (Merleau-Ponty). It is only when the Cartesian cogito is thus clarified, that is to say, revealed to be in a situation, that, as Husserl puts it, "transcendental subjectivity could be an intersubjectivity." It is then that the Ego and the Alter Ego appear to each other, because both he and I have the primordial world in common. On the same level, there is my own vision of myself, just as there is the vision of the other person on himself, at the same time as there is my vision of the other person and his vision of me. My body of natural knowledge - my perceived body - finds in the body of the other person a kind of extension of its own intentions: our two bodies are inhabited by the same anonymous existence. Furthermore, our two bodies realize, or at least give a hint of, expressive and significative movements, 
and form a single system by completing each other, since they are both forms of comportment, or (as Freud said before the phenomenologists) forms of existence or psychic life that signal themselves to each other... I watch the other act: the objects that surround him thereby receive new significations; my world is modified by it, and, as if attracted by it, it ceases to be uniquely mine, present to me. It becomes present to the other, to this other behavior which is destined for my eyes. Its own body is no longer an object, or some kind of fragment of the world, but the site of a certain vision of the world: it is reciprocally engaged with me and becomes, to a certain extent, another me. ${ }^{8}$

As revealed by phenomenological reflection, intersubjectivity appears self-evident. But it is important to note that it responds to a factual truth confirmed to a large degree by a good number of observations realized in the domain of child psychology. Indeed, Henri Wallon and other psychologists have frequently described that stage of infant development in which the child, not yet possessing an awareness of itself or of other people as singular beings, lives in a kind of syncretic sociability, in a perfect lack of distinction between the self and other people. This syncretism of primary relations that intersubjectivity illustrates in a concrete manner as a primordial link to other people is defined by Wallon as "an exclusive and global consciousness that the child has of every situation at the moment when he experiences and imagines it."

Let us also cite Hesnard:

Syncretism is not a nascent personal psychism, but a confused intersubjectivity, that is to say, one's very relationship with the human world, such as it preexists any differentiation, within oneself, of the progressively structured attitude that will clarify one's link to other people.

It is on the basis of this indistinct, intersubjective syncretism that selfawareness, and the awareness of others, is structured in the child. Moreover, it is remarkable that the recognition of other people always precedes the awareness of oneself as a singular being.

This removes any credibility we may give to the formulation of the problem of the relations with other people in the language of traditional psychology. Human relations cannot be thought of in terms of cognitive functions, drives of attraction or repulsion, residing deep within the individual. The link to other people is provided with existence in the form of a co-existence of consciousnesses. As such, it precedes the formation 
of people as private subjectivities and is even the precondition for this process. There is also the question as to how to conceive a differentiation of people - of the 'I,' the 'you,' the 'he' - other than on the basis of an originally global structure in which the terms can be differentiated from each other. To suppose the pre-formed person as a distinct being before any dealings with other people, as traditional thinking had postulated, is just as absurd as abstractly conceiving the right-hand side without any reference to the left-hand side.

The terms of a system - such as, for instance, the system 'me, you, him...' - have never had any sense other than as members of this system that necessarily pre-exists them.

At the end of the day, it appears that intersubjectivity constitutes the terrain in which the multiple forms of relations between individuals are rooted.

We will see further how identification is founded on primordial intersubjectivity in order for it to be structured in relation to private intersubjectivity. We will also see the extreme importance of the notion of intersubjectivity for the comprehension of the specific problem of filmic identification.

This is, in any case, the reason for which we have tarried at such length with a description of it.

\section{Chapter II: Identification}

\section{The Origins of the Concept}

Freud, of course, had the merit of having emphasized the importance of the process of identification in the psychic development of the child. He saw this as the first manifestation of an affective attachment to another person, and assigned it an important role in the formation of the Oedipus complex.

But although Freud assigned the principal role to identifications intervening into the Oedipal conflict, he never excluded the idea of other forms of identification. Certain of his writings prove that he had glimpsed the essential role that identification plays in the totality of our social life, and more particularly in the domain of the awareness of other people.

Let us cite a short extract that serves well to illustrate Freud's point of view on this subject:

What we have learned [...] may be summarized as follows. First, identification is the original form of emotional tie with an object; secondly, 
in a regressive way it becomes a substitute for a libidinal object-tie, as it were by means of introjection of the object into the ego; and thirdly, it may arise with any new perception of a common quality shared with some other person who is not an object of the sexual instinct. The more important this common quality is, the more successful may this partial identification become, and it may thus represent the beginning of a new tie. We already begin to divine that the mutual tie between members of a group is in the nature of an identification of this kind, based upon an important emotional common quality; and we may suspect that this common quality lies in the nature of the tie with the leader. Another suspicion may tell us that we are far from having exhausted the problem of identification, and that we are faced by the process which psychology calls 'empathy' [Einfühlung] and which plays a major role thanks to the possibilities that it opens up in penetrating the soul of people foreign to our ego. 9

These few lines are of fundamental importance, since they allow us to glimpse the richness and significance of the concept of identification. But they equally appear interesting because they contain, at least implicitly, the traditional prejudices which we discussed earlier, and which constitute, we think, an obstacle to the comprehension of these phenomena.

The words "penetrating the soul of people foreign to our ego" effectively show that the idea underpinning Freud's theoretical formulations is that of an ego closed onto itself. Identification with other people should then be conceived on the basis of the perception of common traits, the only means for penetrating and attaching oneself to a psychic reality that is, in principle, foreign to ourselves.

Such a conception, however, engenders a certain number of difficulties.

In effect, if the term 'identification' signifies 'affective attachment,' then the number of common traits is doubtless, if not the precondition for identification, then at least a factor favorable to its development. But if, as Freud indicates immediately afterwards, it also constitutes a means of penetrating other people, we cannot conceive of it on the basis of the perception of common traits. We can see, indeed, that the perception of a common trait, that is, the apprehension of a 'like me,' necessitates, at the very least, the sketch-outline of an identification, without which this trait would not be perceived as common. In order to recognize, in other people, a trait that is common to me, I must have perceived its meaning. We should not say that identification is founded on the recognition of a certain number of common traits - the term 'trait,' incidentally, only corresponds 
to an abstraction without relating to an experience. Rather, through a sketch-outline of identification, which the meaning of the 'ways of acting' of another person already gives me, I can recognize the characteristics that we share.

The difficulties contained in Freud's text drop away if we take the identificatory relation as our starting point - not isolated egos but subjects who are, from the very start, open to the world and to other people. We will then see that it is not traits, variable in number and quality, which are shared between individuals, but the intersubjective link. We will also observe that identification is a mode of behavior that is structured on the basis of this primordial intersubjectivity, and, finally, we will recognize that comprehension and the affective attachment towards others are rooted in identification itself.

Here we return to the theories of Hesnard, who, by rethinking the concept in the framework of a psychology enriched by the gains of phenomenological thinking, has unveiled its true meaning.

Thus, we will now make principal reference to Hesnard, with the goal of optimally pinpointing the signification of identificatory behavior.

\section{Identification as the Behavior of Private Intersubjectivity}

Phenomenological reflection on the one hand, and child psychology on the other hand, have revealed to us the nature of the interhuman link such as it is presented in its origins: an intersubjectivity, a kind of generic co-existence of multiple consciousnesses.

At the beginning of any encounter, this primordial intersubjectivity may be qualified as anonymous because it is elementary, unstructured, and simply inherent to the human condition. As Hesnard points out:

We must insist on the fact that this generic and universal coexistence is anonymous, that is to say that it precedes all forms of identity, personalization, individuation and any other psychic function. With respect to this analysis, let us retain the idea that, given that the world, the primordial world before human knowledge, is not an object for man and that it is in this world that man knows himself. We must be wary of objective psychology and psychoanalysis when they study what they call object-ties.

An object-tie, defined as objectality in the Freudian sense, is already poorly defined. If it is defined by intersubjectivity then it is incomplete, since intersubjectivity is given to the anonymous human being. We must 
therefore endeavor to consider every link between defined, singular, or individual subjectivities as hatching from a soil common to everyone within an intersubjectivity, but structured, that is to say endowed with meaning and value, at the same time as relating to a particular, identified or personalized subjectivity. ${ }^{10}$

In this perspective, identification appears when, against the backdrop of anonymous intersubjectivity, more singular relations are developed and structured - in other words, when anonymous intersubjectivity is transformed into private intersubjectivity. As Hesnard writes:

Here there is a psychic structure, an appearance in the field of intersubjectivity of a posture, or, more generally, a behavior that fashions in each individual, or group of individuals, a disposition towards knowing, and then understanding, other individuals. This often complex or subtle postural disposition presents itself in two often distinct forms: an identification of a given individual with another (or several others), with a we, or a somewhat more anonymous one, and a collective or communal identification, whose sociability largely predominates over its individuality or duality. ${ }^{11}$

Let us make some comments on these lines by following, in the course of our lived experience, the manner in which identificatory behavior is formed in its simplest case - that is, the relationship between two people.

A given individual appearing in my visual field is perfectly unknown to me as a person (that is, as a singular being), but, because this being is structurally similar to me, because they appear to me in a given situation, their behavior already has meaning for me, for the simple fact that I perceive it.

At the same time, they have seen me, and due to this, my behavior no longer belongs to me, strictly speaking, by dint of the fact that it no longer has meaning for me alone. Instead, it also has meaning for this other person, who can read my intentions just as I can read theirs.

First of all, there is the intersubjective link. But, at this stage of the encounter, this link is still impersonal. The individual who I see is still not given to me as a person, but simply as a human being, similar, in this quality, to all other human beings.

It is only when my perception, becoming more active, is structured into an active behavior of apprehending other people that the relation becomes personal. Having been anonymous, the intersubjective link becomes private. 
This active behavior of apprehending another person as a singular being is realized by me through a kind of incorporation of the behavior of the other. In other terms, I identify myself by sketching out the movements of other people in order to comprehend them and grasp them from within. If they speak, I sketch out, while listening to them, the vocal gestures through which they express their thoughts. In extreme cases, it can even happen that, unconsciously, my lips exactly reproduce the movements traced out by the lips of my interlocutor. This quasi-muscular behavior of apprehending other people constitutes the principal aspect of identification. If we are to give an even more striking example, it suffices to think of the movements executed by the spectators when following the twists and turns of an acrobat or the motion of the participants in a sporting contest.

Identification, as a link of private intersubjectivity, is thus that postural behavior by means of which I surpass the simple apprehension of the behavior of other people to actively revive it, through incorporating it or, as psychoanalysts put it, through introjecting it. It is an active fusion of two or several subjectivities entering into a relationship with one another.

We can equally describe it as a complex of projection (or putting oneself in the place of the other) and introjection (putting the other in one's own place), on the condition that we consider this 'other' and the 'self' thus defined, not as already personalized entities but as subjectivities that, at the beginning, are still anonymous and simply opened to each other. It is precisely through the identificatory relation that the 'self' and the 'other', by fusing, mutually appear to each other as personal, singular beings.

At the same time, the relationship thus initiated takes on signification in the domain of affectivity, and is structured according to the multiple nuances of sympathy and antipathy. It is, in fact, on the basis of identification that the feelings of sympathy and antipathy towards other people emerge.

We must not say, as certain theorists think, that it is sympathy that gives rise to identification, or, at least, that sympathy is one of the essential preconditions for its realization. Sympathy, indeed, is nothing other than the affective dimension of the comprehension of other people, and this, as we have seen, is realized in and through identification. Sympathy would thus be unable to exist independently, outside of the behavior of identification of which it is one of the essential aspects.

It might be objected that many instances of sympathy have been born, or at least traced out, spontaneously, as the result of a momentary glance or even upon listening to a mere description, and that it is this initial and sudden sentiment that engenders a disposition that is favorable to comprehension and identification. But, upon taking a closer look, we can see that, if such 
spontaneous feelings exist, then this is because, through this momentary glance that initially gives me a sense for the behavior of others, or through this mere description that informs me of certain ways of acting, I have already been able to apprehend, by means of a barely sketched out identification, a certain manner of being or a certain style of existence. Subsequently, following the signification that this style of existence provides to me, feelings of sympathy or antipathy will be born in an apparently spontaneous fashion. It is very possible, then, that, having been solicited by these initial feelings, identification is extended and structured in a narrower relation. But, in any case, it is certainly because it finds itself traced out that the initial affective reactions have poured forth.

At the end of the day, it does appear that the multiple nuances of sympathy and antipathy are both the affective reflection and one of the factors structuring identificatory behavior.

We would like to illustrate here this final proposition through the examination of a very particular form of nascent sympathy or antipathy: that which emerges from the simple observation of a photograph. This phenomenon indeed arises very frequently, and it might be asked what, in a mere static image of another person, can engender a reaction of an affective nature. In order to understand, we should shift focus to the experience of the observer. When I look at a photograph, the face of the person who is represented to me appears to me with a certain gaze, a certain allure, in a certain position and with a whole series of other elements which I am able to analyze after the fact, but which, the instant that I see them, together form a structure, a structure which immediately gives me the sense of a certain comportment. Thus, I can immediately say of people who are photographed that they are smiling, or speaking, or that they are afraid or serious, etc.

But my knowledge of photographed comportment can go further still. As little as I observe it, a sketch-outline of identification is fashioned in my behavior, a barely traced out postural attitude by means of which I incorporate the behavior observed by reproducing it in a mimetic manner. Thus, I can grasp from within, a little as if it were mine, the attitude taken by the person photographed. I apprehend its meaning as a particular social behavior that is nonetheless revelatory of a more general style of carrying oneself.

Let us note, by the way, that this sketch-outline of the mimetic attitude through which I grasp the meaning of the behavior photographed sometimes finds a more manifest expression. For example, I may instinctively mime the position of the body that I observe, or the severe pout of a person with a particularly austere physiognomy. These are rather rare but highly revelatory manifestations of this incipient identification born from the observation of a mere photograph. 
We can now glimpse the depth with which it is possible for me to comprehend a person of whom I only possess the image. Through this incipient identification that impregnates me with the sense of someone's behavior, a whole style of existence is conveyed to me, a structure or a certain particular manner of being in the world. I may thus say of the person photographed that he appears kind, pretentious, likable, or foolish. Many other qualifiers may nuance my judgment, and they are so many attempts at explaining the form of social existence that it is possible for me to perceive.

At the same time, and in an entirely natural manner, sentiments of sympathy or antipathy spontaneously gush forth. A given countenance, on which I may read amiability, spontaneity, etc., will inspire sympathy in me, while another countenance on which transpires a social attitude that I find unpleasant will arouse antipathy in me.

All these considerations allow us to glimpse the subtlety and astonishing complexity of the process of identification, when we envisage it on the level of lived experience.

Structured on the basis of intersubjectivity, it is above all a postural behavior with multiple, complex, and structural affective repercussions. Its role in the comprehension of other people is essential, and we can thus understand that it is both the origin and the fermentation of multiple relations between individuals and groups, and, subsequently, that it plays a fundamental role in the great and small dramas in the daily life of every individual and every social grouping. Among other things, it allows sympathies to be forged, antipathy and aggression to be formed, social groupings to be constructed, and alliances to be sealed or dissolved. Here, we touch on what Hesnard called the 'dramatic aspect' of identification, and which is, in sum, simply its social dimension.

To refine these notions and clarify these ideas, it is now appropriate to specify the three aspects of identification that we have just evoked: its motor or postural aspect, its affective aspect, and its dramatic aspect. With this goal in mind, we will permit ourselves to cite Hesnard at length. Since this writer has furnished very precise descriptions of these three aspects, we can do no better than simply convey them to the reader.

\section{The Principal Aspects of Identification}

a) The Motor Aspect

We have seen that identification is elaborated on the terrain of private intersubjectivity, in which the motor or postural aspect appears essential. 
As Hesnard explains:

It [identification] is above all a form of motoricity or, if it is observed in a specific situation, a segment of comportment or behavior. But this motoricity is very particular: it is postural. We have here a tonic and durable muscular contraction which affects the muscular systems destined by their functional structure to plastically imitate or copy, in a more or less silent manner, the attitude or the action of another person; to reproduce it in its own way by personally reacting to it, rather than servilely imitating it. This is because the apparent immobility of the subject that visually identifies itself with another person is an immobility full of muscular tension. This tension is felt by the subject by approximatively localizing it, and it can be objectively observed in the form of weak, undulatory expressive movements (in the physiognomy, attitudes, gesticulations) made by the observer. We can say that the observer who identifies interprets the movements of the person with whom they identify while sketching them or tracing them out. ${ }^{12}$

We should clarify that the motor aspect of identification is not a process of simple imitation. On the contrary, it is an interpretative mode of behavior correcting, in a way, the attitude incorporated. The attitude of the spectator whose gaze follows the movements of the acrobat and, while 'miming' them, also corrects them, in a way, is a good example of the interpretation and rectification of the behavior apprehended.

Another example: think of the fleeing gesture we spontaneously make when, at a distance, we see someone who is not reacting to an evident menace.

These examples allow us to glimpse the role that motoricity plays in behavior associated with spectacular identification and filmic identification. But we will return later to these problems which are of particular interest to us.

b) The Affective Aspect

Hesnard writes:

In a normal state, identification is initially - as much in the history of the individual as in the restricted cycle of these durable relations - affectively ambivalent. It is so in the sense that it can orient towards sympathy or love, or it can evolve in the direction of antipathy or aggression. ${ }^{13}$ 
As we have already tried to explain, it is precisely in and through the process of identification, which gives us the 'social mode of being' of other people, that an ambivalent relation finds its initial affective coloring, and is structured according to the multiple nuances of sympathy and antipathy.

\section{c) The Dramatic Aspect}

Man, we said at the beginning of this work, is an essentially relational being. His existence is naturally linked to that of other people by love, friendship, sympathy, aggression, etc., which form a whole spectrum of relations amounting to a vast number of variations of identification.

From the gossip about romantic affairs to the tragedies of hateful, despairing co-existence, from a tiff between friends or joking banter about one's love life to divorce, all-consuming hatred, unexpected suicides and unexplained crimes, all these dramatic events, with their often spectacular outcomes, belong to the dialectic of the couple, that of the master and the slave, the accuser and the accused, that is to say, the intensifications, variations and failures of the links with other people, of identification. Thus is the dramatic nature of identification revealed. ${ }^{14}$

These three aspects of identification, so well described by Hesnard, are far from exhausting the complexity of the phenomenon. There are many others, undoubtedly less important, but whose utility for the comprehension of certain forms of behavior warrants our attention. Such is the case, we would hazard, with the phenomenon of the valorization or devalorization of other people, a phenomenon whose significance can be perceived when we tackle the particular case of filmic identification. It is this aspect that we would like to discuss in greater detail.

d)

Identification as the Basis for the Valorization (or Devalorization) of ther People

As is the case with the affective aspect, nascent identification is, we think, ambivalent on the level of the value attached to a person. It is subsequently oriented either towards a valorization of the people with whom we identify, or towards their devalorization. We can illustrate this aspect by considering the nature of friendly relations.

Friendship doubtless constitutes a stable and profound identification, structured in the course of a durable, recurrent relationship. At the same 
time that it sustains a mutual, highly elaborated comprehension, it finds itself supported by strong feelings of sympathy. Between the members of such a relationship, a common system of thoughts and interests is often established, a similar manner of envisaging people and objects, in short a largely shared mode of existence. At the same time, there is, on the part of each of the members of the amicable relationship, a valorization of the other that advances insofar as the relationship is well-structured. Each friend, to the extent to which they see themselves in their counterpart, forming a community of ideas and feelings with them, attributes to them an unconditional value, a value that they will want to defend in the eyes of others, and which they will not hesitate to exaggerate if necessary.

Alternatively, if this relationship deteriorates, or rather, if the identification that links the friends is destructured, the inverse phenomenon often arises. This mutual devalorization is all the more aggressive when each friend is diminished in the eyes of the other.

This manner of valorizing or devalorizing other people, patent in amicable or amorous relations, exists on the least structured levels of the identificatory relationship, but in a more discreet manner. Identifying with someone, even if this is in a fleeting or barely traced out manner, signifies apprehending a manner of existing which initially appears endowed (or not endowed) with a certain value. Little contact is needed in order to tell whether people are interesting or not, whether they are valuable or not, or whether they possess a remarkable or mediocre personality. In such contact, no matter how brief it may be, there is time for understanding other people, apprehending a certain social manner of comporting themselves, and thus for a confrontation, on the level of lived experience, of the structure of their comportment with one's own. This confrontation of two modes of existence leads to a valorization, or a devalorization, of the people we come across.

It could be thought, upon reading the preceding lines, that this confrontation consists of rational mechanisms of comparison and judgment. In our opinion, however, this is not at all the case. It is quite possible that these mechanisms act on the level of verbal thought, when, for one reason or another, we have been led to explain, even if just to ourselves, our attitude of appreciation or depreciation towards other people. But this is a secondary rationalization. The appreciation of people, their valorization or their devalorization, initially acts on the level of lived experience, before rational thought. Nor should we understand by 'confrontation' a simple process of filtration, through which that which, in the other, is similar to ourselves would be valorized, and that which is not similar would be devalorized. This would abusively simplify the phenomenon. More generally, it is better to 
consider that the sense and the behavioral style of other people, to which I have access via identification, are affectivized, in the field of my own mode of existence, in the sense of a valorization or a devalorization. In other words, the behavior of other people, to whom I have access via identification, endows me with a certain affective signification, which is given a certain affective value.

We are aware that we are touching here on an extremely complex and subtle phenomenon, one which warrants deeper attention and closer description.

We could study, for example, the phenomenon of valorization-devalorization in its relations with affectivity and sympathy, or even rational thought. We could also attempt a classification of different kinds of valorization, and study their effect on human personalities.

Unfortunately, we can only point to these problems, whose analysis would take us too far away from the subject at hand. However, we would still like to evoke, here, certain types of pronounced valorization, whose role in the structure of the personality reveals itself to be particularly effective. Let us think, for example, of the value that parents assume in the eyes of their young children, or the value of particularly brilliant teachers in the eyes of their pupils.

In a general manner, it can be considered that, in these cases, there is, within the identification that links the child to the parent or the disciple to the master, an apprehension of a privileged mode of being of the lived world. This mode of existing will then be valorized to such an extent that it will often become a behavioral model, and thus a factor in the formation of the personality.

We will return to such phenomena of extreme valorization when we envisage different aspects of filmic identification. It will then become evident that this particular type of identification can engender a valorization of the film character that goes as far as excessive idealization and even 'divinization.'

The few aspects of identification that we have just summarily sketched out are far from exhausting its complexity. We can perceive how useful it would be to pursue its analysis at length. We should hope, however, that this exposition is sufficient to glimpse the importance of identification in our psychic lives.

Identification, as we know, is of interest to the totality of the human being. It is the fundamental wellspring of the apprehension and comprehension of other people. It is both the fermentation and the structuring factor of our social relations. It appears in the first hours of our existence and continues 
to act on a permanent basis, sometimes in a patent manner easily observable from the outside, but most often in a discreet, interiorized manner.

It is even present when, withdrawn into isolation, we give free reign to our imagination. Often, the dream is merely the identification of the self with a dreamed ego, projected in a more or less chimerical universe which reorganizes reality in the sense of our projects and desires.

Let us note that, in the reality of our daily relations, identification, as the behavioral form of comprehending other people, is most frequently structured in a relation of reciprocity, a relation through which each of the subjectivities in interaction, while impregnating their counterparts, conserves their own autonomy and self-consciousness. In such a relation of reciprocity, other people are present in my consciousness, as well as my view of them and their view of me, which constantly refers to my behavior, and which has the result that I am incapable of forgetting myself.

But when, outside of any reciprocity, we are only the remote spectator of the actions of other people, identification can become absorbing to such a point that it abolishes almost all self-awareness. As we will see, this phenomenon attains its highest degree of realization in the identification with a spectacle, and above all, in filmic identification, a kind of fusion of the actor and the spectator in the same behavior, represented in an effective manner by the former and posturally experienced by the latter. We will return to this problem later.

As we can see, identification subtends the most diverse types of interhuman relationships. Whether this is in the spectacle, in direct contact with other people, or even in our imagination, identification is what allows us to psychically live with other people.

As Hesnard writes:

Identification with another person, which can be complicated by identification with oneself, and which extends within itself the concrete, external drama of existence, results in there being nothing of any importance in the thought or action of each of us that is not what we take from other people, what we give them, and what we believe to be the judgment of others on us. Obscure and without any effect when it comes to other people with whom we are only linked by generic intersubjectivity, this presence of the other person in us is formulated or appears reflexively to us with respect to all those who we have loved or desired: parents, friends, teachers, those who inspire our intellectual or social activity. [...] If nothing of what is human is foreign to us, this is because, as subjectivities who are separate but in communication with each other, we identify ourselves with all the actors in the drama of our existence, up to the 
testimonies that they leave on events. We could almost say that man is an anthropomorphic animal - an anthropomorphosis, if you will - and is born from the projective element of natural identification. This can be understood if we admit that identification, as a generalized style of comportment, is only the private aspect of anonymous intersubjectivity that the primary behavior of man expresses. And it is also what conditions in each human being their comprehension of those who are akin to them. ${ }^{15}$

\section{Fleeting and Structuring Identifications}

The forms of social relations are too numerous for us to attempt, within the limits of this work, a systematic exposition of the multiple variations of identification. Such an attempt would doubtless lead to an abusive and rather artificial schematization of reality.

However, in light of the goal of furnishing this book with the means for studying identification as a form of influence, we can distinguish, from among the different types of identificatory behavior, those which are fleeting and most frequently without any effect on the personality from those which are stable and structuring. The former are sketched out in the multiple contacts of our daily life. The latter are realized through shared life and recurrent encounters with other people. Among them, we can cite identification with one's parents, which contributes in a determinant manner to the formation of the personality, and the assimilation of moral and cultural norms. We could also cite the identification of pupils with teachers and the more prevalent identification of adolescents in search of privileged models of behaviour.

In short, in a general manner, we can qualify as 'structuring' those identifications which, in one way or another, exercise an influence on the personality. We could also note that stable identification can still be variously qualified according to the modalities of its realization. It can be alienating or liberating, successful or failed, or even healing. But here it is a question of nuances introduced by psychoanalysis, and which are only of distant interest to the preoccupations of the present study.

\section{Identification, Projection, Introjection}

The terms identification, projection, and introjection have often been employed in a confused way, or in different senses by different authors.

In order to avoid any confusion, we would now like to precisely clarify the meaning of each of the terms in the framework we have adopted. 
Our point of view on this subject does not question the aptness of the concepts in the framework of psychoanalysis, or the definitions that they have received in this same framework. It does not enter into our competence to judge either this aptness or these definitions.

But, with the goal of avoiding the equivocations that may arise in the rest of this work, we believe it is useful to define our opinion, and to clarify the exact meaning that we will give to the terms under examination here.

In a very general manner, it could be said that projection and introjection are two aspects of a single phenomenon: identification as a form of private intersubjectivity. In our view, we should not see in these terms two distinct phenomena that together form identification by succeeding or completing each other in a simple synthesis.

If we have used, with respect to a single phenomenon, the apparently opposed concepts of projection and introjection, then this is because, for those who experience it, identification, as the behavior of actively apprehending other people, can also be qualified as a placing of the self in the other (projection) or a placing of the other in the self (introjection). The two terms refer to this same behavior of apprehending other people. They are simply two ways of expressing one and the same behavior.

Identification is a form of intersubjectivity, that is, a coexistence of consciousnesses, or a fusion of subjectivities, in a behavior of mutual apprehension. Thus, to speak of the self and the other, of a projection of the self or of an introjection of the other, no longer has any significant meaning. In our view, they only amount to two different ways of shedding light on one and the same phenomenon, the subject who, having been liberated, and having been able to recuperate its identity, is forced to express itself by making reference to the two terms in the relationship - the self and the other person - and must therefore make its choice between the two possible combinations: 'placing of the self in the other' and 'placing of the other in the self.'

We could, however, oppose to this point of view the observed existence of certain phenomena whose explanation seems to necessitate the distinction between the two components: projection and introjection.

Thus, the existence of different appreciations of the subject of a single person or a single form of behavior seems to be able to justify a conception of identification, conceived of as a composite of two processes - projection and introjection - with projection being the cause of the multiple distortions that the appreciation of other people can suffer.

How to respond to this objection? If we initially reflect on the different ways of appreciating a person, we can observe that the explanation advanced neglects to think that the personality is not a stable object, identical with 
itself, and that a good part of the differences between the perceptions and interpretations of the different ways that people have of behaving comes from the fact that these people take on variable attitudes and structure their comportment differently depending on the interlocutors they meet and the types of relations that they establish.

Subsequently, having abstractly considered the malleability of other people, we should still consider that the behavior apprehended by identification is interpreted in different ways according to our personalities, or, rather, the specific mode of being of each individual.

To explain this, it is not necessary to have recourse to the complex interplay of the mechanisms of projection and introjection, whose respective parts in the behavior of identification would condition the value or the objectivity of the comprehension of other people. Simply put, the comportment with which we identify in order to understand it is given a specific perspective, which depends on our own manner of structuring our existence, and thus, on our system of values. Hence, a given behavior, which I apprehend, and which appears to me, against the backdrop of my own system of values, as intelligent, or valid, or nonsensical, might appear to other people as ill-adapted or without value, etc. And yet neither this other person nor myself are mistaken on the meaning of this behavior.

It is only because we each categorize the real according to a system that is specific to us, that this behavior receives, for each one of us, a particular signification.

Alternatively, we can consider by attribution, occasionally observable in certain particular situations, very different meanings in the same behavior. A good example of this phenomenon is provided to us by the examination of responses given to projective tests (the Thematic Apperception Test, Rorschach tests, etc.). The same image arouses responses that perceptibly vary according to the subjects tested. For example, we sometimes say of people who have an ambiguous attitude that they are dreaming, crying, or sleeping, etc. Is identification, in these cases, reduced to its mere projective component? This would, evidently, confirm the idea of identification as a composition.

In order to understand these supposed pure 'projections,' we must take into account the fact that, in these cases of identification, reciprocity and exchange are lacking. There is, on the one hand, a neutral behavior (simply visualized in the case of projective tests) and, on the other hand, a subject who identifies in an active behavior of apprehension encountering no reciprocity or exchange. Thus, when we demand that the subject express what they have perceived in the other, it is self-evident that aspects of their 
own subjectivity appear. Is this to say that there has been a projection of subjectivity in the other, and thus that we have managed to isolate the 'projection' component of identification? It seems to us that this is not the case, since nothing, in the experience of the subject who identifies, allows us to conclusively determine the autonomous existence of this kind of transferal of the self into the other. On the level of lived experience, identification is a form of intersubjectivity (that is, the fusion of subjectivities). But, precisely, because one of the elements of the relationship is neutral, and identification is unilateral, this fusion of subjectivities is a one-way process and only lets one of the subjectivities transpire, that of the subject who is actively apprehending. We can then speak of projective identification, signifying by this that it is conducive to revealing the personality of the subject who identifies. But we can in no way speak of 'projection' and 'transferal' as autonomous processes. These terms may well designate the result of 'projective identification,' but they do not imply anything about nature, or its composition.

In the same manner, we can designate with the term 'introjection,' not a process, but the result of what we may call introjective identification. In order to illustrate this last type of identification, let us recall the situation of the psychological interview. In this situation, the interviewer, whose goal is to understand the interviewee, effaces himself in order to better enable the subjectivity of the other to transpire. There is introjective identification, with a one-way intersubjectivity brought about, in which only one of the subjectivities in the relationship, that of the interviewee, expresses itself.

We will conclude by saying that identification can be projective or introjective to the extent that the intersubjectivity that characterizes it is fixed on only one of the subjectivities in the relation.

From the point of view of the subject who identifies, we can speak of projective identification when intersubjectivity is crystallized around one's own subjectivity, and introjective identification when intersubjectivity is fixed on the subjectivity of the other.

Thus, when we speak later of filmic identification, it should not be considered as a mechanism of the projection of the spectator, or introjection of the character, but only as a relation of intersubjectivity linking the spectator and the character.

\section{Identification, Mimicry, and Imitation}

The concepts of mimicry and imitation can also give rise to diverse interpretations. In order to eliminate any confusion, it is important to clarify what they refer to in the perspective that governs this study. 
By 'mimicry,' we understand the posturo-motoric behavior that constitutes the principal aspect of identification. We have already had the occasion to clarify the nature of this aspect. Let us simply recall that mimicry is the active behavior through which the subject who identifies tends to posturally reproduce the comportment of the person with whom they identify. This is a motoric behavior, sometimes patent but usually discreet, and occurring in an unthinking way.

We have given several examples of rather manifest mimetic behavior. In order to illustrate the phenomenon one last time, let us recall the example of spectators who trace out and reproduce the gyrations of acrobats whose movements they follow when identifying with them.

Contrary to mimicry, which is an apprehensive comportment, imitation can be characterized as reproductive comportment.

We could define it as follows: a comportment seeking to consciously reproduce, with various goals, the behavior that is apprehended through identification. Following the goals sought after, we can distinguish several forms of imitation.

Some forms of imitation take place within spectacles: their objective is to caricature a character. Others simply strive to reproduce the behavior of an individual or a group of individuals, to better explain or depict it. Still others aim to reproduce in reality modes of comportment with which we can identify, and which are highly valorized. These more important forms of imitation warrant our focus for a while.

Anticipating the second part of this study, we can illustrate this type of imitation with the numerous examples that are offered to us by what we can call the extensions of the cinematic spectacle in our individual and social life.

We know all the phenomena provoked by the cult of the movie star. An actor or an actress encounters the favor of the mass public, and the manner, the bearing, the facial expressions, and even the clothing of this actor or actress are immediately copied by a significant section of their admirers.

How can these facts be explained?

Briefly put, we can sketch out this genesis as follows: on the screen, the star presents a comportment, or rather, a privileged mode of social existence. The spectators who identify with the star during the screening valorize this exceptional mode of existence, whose advantages on the social level appear self-evident. Thus, in order to valorize themselves, they tend to appropriate the characteristics of the star, to reproduce their mode of existence, to embody the same signification. In other words, they will try to present themselves in the eyes of other people an image of themselves similar to that of the valorized actor or actress. 
This intentional appropriation of the behavior of other people can also be called imitation.

The question remains open to know if there exists, alongside such fleeting imitations, more structural imitations. We can ask ourselves if, in extreme cases, structural imitations are not equated with what we called structural identifications.

Probably, at a certain level, the vocabulary becomes uncertain and the distinctions become rather artificial. Whatever the case may be, in a general manner, we will reserve the term 'identification' for the active behavior of apprehending other people, the term 'imitation' for the intentional behavior of reproducing the comportment of other people, and the term 'mimicry' for the posturo-motoric aspect of identification.

\section{Identification and Personality}

We have tried to study some of the major principles concerning the very nature of the phenomena of perception, intersubjectivity and identification. We have also spoken of 'personality' in terms of the 'mode of existence,' the 'manner of being in the world' or the 'manner of structuring one's social relations.'

It has thus become easier to sketch out a more systematic definition of the personality. This will be the object of the present section. We will try to present a certain conception of the nature of the personality, a conception which, we think, could be useful to filmological reflection, and to show the preponderant role played by identification in the formation of the personality.

What, then, is the personality? The concept of the personality evokes a whole series of other concepts, with a rather widespread usage in psychology, as in everyday language: 'temperament,' 'character,' 'Ego,' 'characteristics' or 'personality traits,' etc., so many terms which all, aside from a few nuances, refer to a reality situated within the individual.

Often, indeed, the personality (or the temperament, etc.), is considered as one of the internal entities or psychic objects, and we can then ask ourselves what, in these objective realities, can be attributed to heredity or to the environment.

Since the problem cannot be solved scientifically, a compromise is often established. Heredity is ascribed to the original nucleus, and the environment to the modification and reorganization of this nucleus. In this perspective, we often call 'temperament' that which is innate, and 'character' what this temperament becomes in the environment that has modeled it.

In any case, reference is always made to a kind of internal entity, an objective reality inscribed in the psychism as a biological trait. 
It may well be true that the depiction that we have provided here of a certain classical conception of the personality is rather caricatured. But, in spite of the nuances that we have neglected to expose, there remains the fact that, in everyday thinking as well as in the great majority of theoretical conceptions, the term of the personality almost always designates an internal, objective, and therefore relatively stable entity.

And yet, as with the old conception of perception evoked at the beginning of this study, such a mode of thinking derives from what the phenomenologists have called the 'prejudice of the world.'

To posit, as the starting point for this reflection, the world as a reality external to the individual, and the latter as an individualized entity closed in on itself, leads us to think of the personality as an internal, objective reality, one that is given from the very beginning, whose function it is to give form to comportment in general and, more particularly, to social comportment.

And yet, what does this lived experience teach us about these supposed internal realities?

First of all, the personality appears much less stable than we would often like to imagine. 'Comportment,' such as it is experienced, is a fluid, changing reality. In order to take stock of it, it suffices to think of the changes in attitude and comportment of an individual according to the milieus in which they are successively inserted, and the different people with whom they associate. Of course, there is a constancy to comportment, a general manner of conducting oneself, which constitutes, precisely, what we call the personality. But the suppleness of this general manner of conducting oneself already underlines the relational signification of the personality. Behavior is always, in fact, formed on the basis of specific relational situations.

The relational character of the personality will be even more apparent if we interrogate the nature of the constant aspects of the personality. Let us take as an example the well-known phenomenon of paranoia. In order to understand the paranoid, or paranoiac, individual, it is necessary to refer to the insertion of the individual in the interhuman world. Paranoia, even in its attenuated forms, is essentially a social mode of comportment. Its signification can only be understood in and through the network of interpersonal relations of the individual.

We could doubtless say that paranoia, as a mode of social comportment, did not develop by chance, and that something needed to exist within the temperament in order to provoke it. It is quite possible that this something exists, that there is a biological structure favorable to the onset of paranoia. But, in any case, this structure cannot be considered as the sketch-outline of paranoia: it cannot even constitute its cause. It is only one of the numerous 
elements that, in the field of the social relations of the individual, have contributed to the structuring of paranoiac or paranoid behavior.

Another example would allow us to better understand this idea.

Biometric and typological studies have established a correlation between the mental structure and the anatomic structure. Thus, it has appeared that malingering individuals are usually schizothymic, closed off, and introverted. Does this mean that asthenics (as they are called) bear, inscribed within themselves, at the same time as their bodily structure, the germs of schizothymia and introversion? This would amount to saying that, prior to any social insertion of the individual, the form of one's social comportment is already structured. It appears more reasonable to think that, having taken account of a certain anatomo-physiological substrate, the manner in which individuals structure their comportment within the multiple social interactions will normally be oriented towards schizothymia and introversion, or towards cyclothymia and extroversion. Thus, to focus on anatomic structure alone, it is evident that physical asthenia, which is experienced by the asthenic individual as a certain mode of being in the world and a certain way of appearing to other people, contributes, in the fields of interpersonal relations, to the formation of a certain behavioral structure oriented towards timidity and introversion.

In short, all this shows us that we should consider the personality not on the basis of the isolated individual, but rather on the basis of the insertion of individuals in their interhuman milieu. What is primary in man is the need for relationships. We thus come back, here, to what perception and intersubjectivity have taught us.

Perception, indeed, has shown that man is, from the start, a 'being-inthe-world' and a 'being-with-other-people.'

Intersubjectivity, as a generic co-existence of consciousnesses, has revealed to us that the nature of man is to be a relational being, that the individual can only be understood as a node of relations. We thus understand that the personality is none other than a certain singular mode of being in the world and with other people. It is the manner in which each individual structures their interpersonal behavior. Born within primordial intersubjectivity as a generic link to other people, it is the manner in which each subjectivity is constructed in and through the complex interplay of multiple identifications that link the individual with others: identification with one's parents, identification with one's mentors, identification with cultural or moral models, group models, etc., as well as identification with oneself and the image one offers to other people. 
In short, the personality is a singular manner of social existence, which is structured within the multiple interpersonal relations in which identification plays a preponderant role.

Having admitted this, we can now clarify what we mean by the notion of the interpretative system of the personality.

In this optic, any system of interpretation or evaluation of the personality essentially consists of a systematic set of categories and notions serving to specify the modalities of being in the world.

We can also better clarify the role of research when it has the goal of studying the modifications of the personality when subject to the influence of various factors.

Hence, to ask ourselves whether a given factor can modify or influence one's personality or comportment, first means seeking the lived signification of this factor, and then seeing how the apprehension of this signification can modify the social manner of being, or the social mode of existence of the individual.

Thus, asking whether filmic identification can influence a personality initially involves attempting a description of the lived meaning of the phenomenon of filmic identification, and then seeing if this phenomenon, whose lived repercussions and affective resonances we know well, can contribute to the structuring of the personality, or rather, to the structuring (or restructuring) of social modes of comportment. We will return to this problem later.

\section{Identification, Communication, and Information}

Specialists in the social sciences have often characterized communication as the simple transmission of a message from a sender to a receiver. The stages of the process presented in this fashion are: formulation of the message, its encoding or translation in a system of signs, and the emission, transmission, reception, and finally decoding which provides the receiver with the meaning of the message.

Such a schema offers, of course, a convenient tool for thinking of communication in scientific terms. But this apparent scientific objectivity can only, unfortunately, be obtained by neglecting an important element. It is indeed often forgotten that communication is just as much an affective as a cognitive phenomenon.

Let us cite Lagache:

If communication is that through which an individual influences another individual, and is influenced by another individual, then it is not only the 
cognitive content that constitutes the essence of the message, but also the affective halo that accompanies it.

And yet, in the particular case of verbal transmission, what exactly does this affective aspect of communication consist of? It essentially relates to the identification in the relation that links individuals through communication - that links, that is, the listener (or listeners) to the speaker.

We all know by experience that an adequate understanding of the discourse of an interlocutor or lecturer can only be attained by mobilizing a certain degree of identification. We 'put ourselves in the shoes' of the person speaking in order to adopt their comportment and better understand the lived experience of the words they utter. If there is any need to convince ourselves of this point, it suffices to recall the example (cited earlier) of the listener who, in certain pronounced cases of identification, unconsciously repeats the vocal gestures of the interlocutor.

It thus appears that communication, far from being reduced to a cognitive operation, is only realized to a high degree of perfection in a climate of intersubjectivity.

Pushing this analysis further, we can even perceive that the relations between identification and verbal communication, and even communication in the more general sense, are much more profound that we might think.

Is it not, in fact, in the primordial and generic intersubjectivity which initially links people to each other, that we should seek the first form of communication and the terrain on the basis of which the most structured modes of communication (like language, for example) are elaborated?

Hesnard answers this question in the affirmative. Speaking of primordial intersubjectivity and of primary identification, he writes:

Expression through language is the culmination of the concrete gestural expression, born of a primary mimetic identification and expressed through the muscles, then becoming structured in thought, which is incarnated in the laryngo-vocal gesture. ${ }^{16}$

In this perspective, not only does identification appear necessary to the realization of verbal communication, but also, reversing the terms, we can even say that language itself, through the immense possibilities it offers to expression, is a tool at the service of the interhuman link of identificatory behavior.

What we have already said concerning the role of identification in verbal communication can also be applied to all forms of communication, 
beginning with writing. To understand, to discover the significations in written words, is not simply a process of decoding, but involves apprehending, through writing, the significations experienced by a particular subjectivity. It involves, that is, identifying with the author. Hence, any lack of understanding of a text, unless it is written in an unknown language, is not linked to the shortcomings of a decoding grid, but is usually due to an incapacity for identifying with the author of the text, of 'putting oneself in their shoes,' and thus grasping the living significations of the words employed. We are thus confronted with an incoherent assemblage of phrases that are incomprehensible because they are lacking in any affective resonance.

In the end, identification equally has a word to say about what could be termed 'artistic communication.' Understanding a work of art, a painting or a musical work, involves apprehending, through colors, forms, or musical movements, an affective structure specific to a certain subjectivity.

Here again we identify with and relive the experience of the author, and this is what permits the spectator to then affirm, of a painter or a musician who has never been met, that they are passionate, sad, tender, or sentimental, etc.

As for the cinema, we will soon see that it is indisputably the art form which permits the highest degree of identification and that, by dint of this fact, its possibilities in the order of the comprehension of humans are considerable.

To conclude this section, let us cite some lines from Merleau-Ponty, conducive to giving us a presentiment of the virtualities of filmic identification:

This is why the movies can be so gripping in their presentation of man: they do not give us his thoughts, as novels have done for so long, but his conduct or behavior. They directly present to us that special way of being in the world, of dealing with things and other people, which we can see in the sign language of gesture and gaze and which clearly defines each person we know. If a movie wants to show us someone who is dizzy, it should not attempt to portray the interior landscape of dizziness, as Daquin in Premier de cordée and Malraux in Sierra de Terruel wished to do. We will get a much better sense of dizziness if we see it from the outside, if we contemplate that unbalanced body contorted on a rock or that unsteady step trying to adapt itself to who knows what upheaval of space. For the movies as for modern psychology dizziness, pleasure, grief, love, and hate are ways of behaving. ${ }^{17}$ 